\title{
Как перейти от борьбы за доминирование к совместному развитию
}

\author{
И. Покровский ${ }^{1}$
}

УДК 334.021 | ВАК 05.13 .10

\begin{abstract}
Движущей силой экономики до сих пор были идеи доминирования. Как захватить рынок? Как удержать рынок? Как вытеснить конкурентов? Цифровые технологии расширяют возможности подчинения заказчиков и вытеснения конкурентов. Но такая борьба теперь не обеспечивает рост экономики, а разбалтывает ее и создает всё более высокие риски. Чтобы вернуться к развитию, нужны идеи, которые позволят преодолеть зависимость от существующих доминирующих игроков, не устанавливая новых.
\end{abstract}

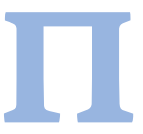

о мере насыщения рынков идея захвата исчерпывает себя. К настоящему времени мир «людей потребляющих" освоен и поделен между крупнейшими транснациональными компаниями, как когда-то были освоены все континенты и поделены между империями. Остались удаленные острова рыночных ниш и пустыни неплатежеспособных сегментов. Усилия по захвату рынков теперь - дележка пирога без изменения его размеров, а чаще с ущербом для рынка.

\section{МОНОПОЛИЗАЦИЯ И ЦИФРОВЫЕ ПЛАТФОРМЫ}

Основным оружием в борьбе за рынки в последнее время стали технологические и цифровые платформы. Первые основаны на совместном использовании базовых технологий и других технических ресурсов, вторые - на совместном использовании больших данных.

Цифровая платформа - это информационная система, которая позволяет интегрировать различные приложения и устройства в общий процесс сбора, хранения и обработки данных. Приложения и устройства могут использовать совместно собираемые данные, а также общие инструменты хранения и обработки больших данных.

Под технологической платформой, как правило, понимают сочетание аппаратной архитектуры, интерфейсов и системного ПО.

Платформы совместного использования очень эффективны в конкуренции с закрытыми вертикальноинтегрированными решениями за счет существенного

Ассоциация разработчиков и производителей электроники, исполнительный директор. снижения стоимости. И они чрезвычайно эффективны в установлении зависимости заказчиков, а также в подчинении партнеров. Использование технологической зависимости дает существенно больший эффект, чем административное подчинение. Технологическая зависимость заказчиков и партнеров позволяет владельцам платформ использовать сетевые методы управления и самоорганизацию, обеспечивает гибкость и адаптивность подчиненной системы, высокую эффективность обратных связей.

В пределе возможности для предпринимательства остаются только у владельца платформы. Остальные, условно называемые "партнеры", переходят в категорию работников, которые продают свой труд. Хотя это выглядит, как предпринимательская деятельность, высочайшая конкуренция "партнеров" между собой в рамках правил, заданных платформой, приводит к тому, что цена падает до стоимости труда. Прибыль, как следствие, инвестиционные возможности, а вместе с ними и лучшие кадры, доступ к самым передовым технологиям и другим ресурсам концентрируются в ядре экосистемы у владельца платформы.

На рынке производителей компьютеров доминирующую программно-аппаратную платформу Wintel составляют процессоры х86 компании Intel в сочетании с операционной системой Windows; на рынке мобильных устройств - процессоры на основе архитектуры ARM в сочетании с операционной системой Android; на рынке автоматизации сейчас разворачивается конкуренция за доминирующее положение между платформами Интернета вещей.

Промышленные монополисты прошлого не имели такого глобального охвата и не оказывали такого влияния на поведение заказчиков. 
Особенности нового этапа монополизации - технологической и цифровой - заключаются в следующем.

Во-первых, данная монополизация не только экономическая. Это еще и доминирование в стандартизации, обучении специалистов, шаблонах технических решений, а также поведения пользователей.

Вторая особенность - скорость захвата рынков. Для цифровых платформ нет барьеров расстояний и почти нет издержек на подключение новых пользовательских устройств. В то же время конкуренция идет в первую очередь за большие данные: кто замкнул на свою платформу больше пользователей, больше разных приложений, больше компаний-поставщиков, у кого в результате больше данных, тот выигрывает. Специфика результатов монополизации состоит в том, что, замкнув на себя потоки данных, компания получает существенно большее влияние, чем замкнувший на себя заказы поставщик товара.

Третья особенность в монополизации прав на большие данные, а также на управление коммуникациями между заказчиками и поставщиками. Цифровая трансформация со всеми ее перспективами состоит в основном в переподчинении рынков цифровым платформам. Наиболее яркий и понятный пример - яндекс. Такси. Партнеров платформы с трудом можно назвать предпринимателями. И возможностей для самостоятельной деятельности на этом рынке практически не остается. Если машины нет в Яндекс.Такси, то в Москве это уже не такси, потому что с некоторого времени никто не поднимает руку, чтобы проголосовать на дороге, никто не звонит по телефону, реклама такси потеряла смысл, такси выбирают и заказывают исключительно через приложение, а из приложений выбирают то, где больше всего машин, то есть Яндекс.Такси. Пользователь привыкает обращаться к рынку исключительно через определенную цифровую платформу.

Маркетплейс, как один из самых распространенных видов цифровых платформ, занимает место в коммуникации между заказчиками и поставщиками. Раньше эти коммуникации принадлежали поставщику, он мог звонить или встречаться с заказчиком, убеждать его, продавать активно. Новое поколение заказчиков вырастает на маркетплейсах и смотрит на рынок только через них. Если поставщика нет на маркетплейсе, значит его нет на рынке. В каждом сегменте рынка определяется или уже определилась своя доминирующая цифровая площадка, и поставщики не смогут отказаться от нее и будут платить владельцу платформы всё больше за различные премиальные сервисы по продвижению своей продукции, а также брать на себя всё больше обязательств перед заказчиками и владельцем маркетплейса.
Также мы видим, что цифровые платформы зависят от технологических платформ. Часто последние контролируются владельцами крупнейших в мире цифровых сервисов. Например, Яндексу нужен доступ к устройствам пользователей через платформу Android, которая принадлежит американской компании Google. И яндекс.Такси подчиняется всем правилам этой платформы, например не работает в Крыму.

Особая ситуация с компанией Amazon. Кроме того, что она - маркетплейс, она еще и крупнейший в мире поставщик веб-сервисов для маркетплейсов (дочерняя компания AWS). То есть конкурирующие с ней маркетплейсы работают на оборудовании и пО, которое принадлежит AWS. Что будет, если ресурс ЦОДов по каким-то причинам будет ограничен, например из-за аварий, сбоев? Какие маркетплейсы в первую очередь получат поддержку? Ответ очевиден. Но достойной альтернативы AWS нет, у нее самая большая доля на мировом рынке веб-сервисов.

Цифровизация обеспечивает более высокую скорость масштабирования сети партнеров, что сокращает срок вытеснения конкурентов крупнейшим игроком [1]. В условиях насыщенных рынков это вызывает монополизацию и технологическое единообразие. А это, в свою очередь, неизбежно приведет и уже приводит к застою и общей неустойчивости экономики. у «партнеров" нет запаса прочности для того, чтобы пережить даже незначительные трудности. Кроме того, знания, данные и связи, необходимые для развития, владельцы платформ замыкают на себя и выдают партнерам уже в обработанном виде как указания и стандарты. При этом доступ к платформе может быть ограничен множеством факторов, начиная с государственного регулирования и технических проблем и заканчивая управленческими решениями владельца платформы.

Технологическая зависимость России сейчас определяется в основном как зависимость от других стран.

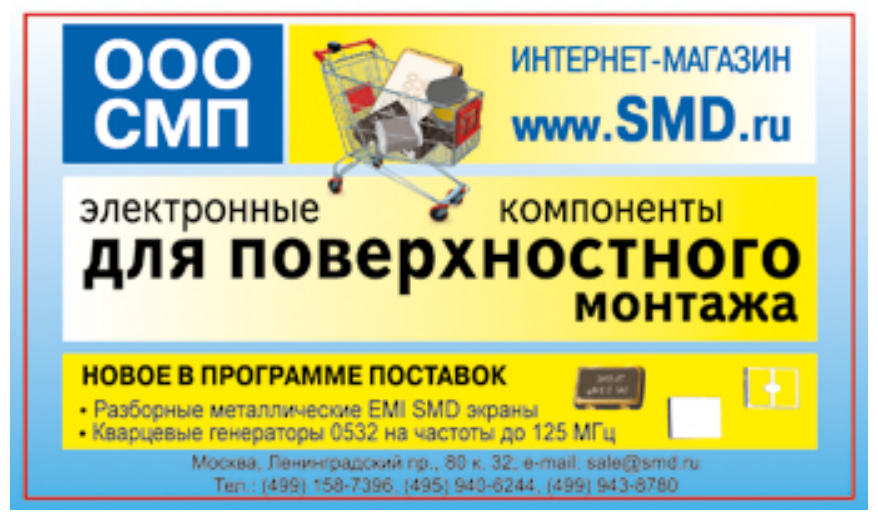


Это не совсем так. Все страны мира находятся в технологической зависимости от крупнейших транснациональных компаний. Зависимость не от стран, а от компаний, доминирующих в своих сегментах, подчинивших себе глобальные рынки, гораздо более важный фактор, он является первичным. Государства используют зависимость от своих компаний в политических целях и, конечно, поддерживают их доминирование [2]

Монополизируя рынки, компании концентрируют на себе риски, создают ситуацию неустойчивости. Чем меньше конкурирующих игроков, тем меньше точек опоры. В движении и развитии еще можно балансировать на двух точках опоры, даже на одной. Но если движение замедляется, если, как в последнее время, перестает расти рыночный спрос? Тогда еще некоторое время можно расти за счет поглощений и слияний с игроками смежных сегментов, концентрируя на себе еще больше рисков

В настоящее время это приводит к раскачиванию цен и сроков поставок, к проблемам доступности продукции, производство которой монополизировано. Чем меньше остается конкурирующих игроков, тем меньше эластичность предложения. Если из-за стихийного бедствия или эпидемии останавливается фабрика, которая обеспечивает весь мир, то за несколько месяцев дефицита заказчики теряют больше, чем они выигрывают за годы снижения себестоимости от эффекта масштаба. Государство, в котором расположена такая фабрика, может шантажировать другие страны. И этот шантаж может быть взаимным, как, например, в прошлом году между Южной Кореей и Японией [3]. Первая по политическим мотивам отказалась поставлять чипы памяти, а вторая в ответ отрезала поставки чистой химии для полупроводникового производства. В результате - дефицит, срывы поставок и рост цен практически на ровном месте. Сейчас взаимно шантажируют и душат друг друга США и Китай. И то, что мы видим в лентах новостей, скорее всего, только начало проблем. Пока эти удары по рынку демпфируются большим числом дистрибьюторов, их диверсифицированными каналами поставок и складами. Но и здесь процесс монополизации идет очень быстро. Глобальные производители сокращают число своих дистрибьюторов, присваивая себе маржу, формируемую в каналах поставок. В первую очередь под сокращение попадают локальные (национальные) дистрибьюторы и дилеры. Также вендоры сокращают вознаграждение глобальных дистрибьюторов, что лишает их возможностей обеспечивать, как раньше, буферные функции. Всё больше клиентов переводится на прямые поставки от производителя. И это еще сильнее снижает устойчивость отраслевых экосистем и повышает риски. Характерный пример на рынке электроники: Intel купил несколько лет назад одного из двух ведущих производителей программируемых логических ИС (FPGA) - компанию Altera, разорвал дистрибьюторские соглашения с большинством прежних партнеров этой компании во многих странах, передал права поставок единственномуглобальному дистрибьютору, урезав дистрибьюторскую маржу более чем в два раза. Кроме этого, значительная часть ранее выпускавшейся номенклатуры Altera была признана несоответствующей стратегии Intel, и ее производство было прекращено. А на этой номенклатуре было разработано, производилось и эксплуатировалось оборудование для информационных инфраструктур, промышленной автоматизации, транспорта и безопасности. Тысячи производителей электронного оборудования в разных странах остались без комплектующих и поддержки. С очень большими потерями они переводят свои проекты на компоненты Xilinx, другой американской компании, которая на пару с Intel-Altera занимает около 90\% мирового рынка FPGA. У этих заказчиков, таким образом, осталась одна точка опоры. Поддерживать устойчивость в дальнейшем им будет еще сложнее.

То, что приводимые примеры относятся к электронике, не означает, что других отраслей это не касается. Просто в электронике это проявляется ярче, так как отрасль является наиболее глобализированной и одной из наиболее оцифрованных.

Пример с Intel-Altera иллюстрирует процесс монополизации и централизации, который идет широким фронтом по всем отраслям, и не важно, управляется он “невидимой рукой рынка" или своекорыстными интересами. Однако когда наступает момент насыщения, когда расширяться некуда, нерегулируемые ничем своекорыстные интересы начинают заводить экономику в упадок. Мир сейчас находится в точке такого перелома.

Текущий кризис часто сравнивают с предыдущими, выделяя лишь определенные особенности. Ведь и раньше говорили о системных проблемах, но ихудавалось решать без серьезных изменений в структуре мировой торговли. В рыночной экономике регулярно возникают проблемы перегретых ожиданий, перепроизводства, финансовых пузырей. Глобализация экономики в целом и финансовых рынков в частности привела к тому, что даже локальные кризисы нередко откликаются проблемами во всем мире. Такие локальные проблемы научились решать: поднять платежеспособность населения кредитами, влить деньги через государственные заказы, влить деньги без государственных заказов, списать долги банкротов и т. д. Всё для того, чтобы внимание потребителей не 
фокусировалось на причинах проблем и рисках, так как ответственное отношение заказчиков больше всего мешает раскручиванию спроса на продукцию крупнейших глобальных корпораций.

Перечисленные антикризисные рецепты работали, пока выполнялись два условия: во-первых, удавалось втягивать в мировую экономику новых потребителей и, во-вторых, глобальные корпорации могли увеличивать свою долю и повышать эффективность за счет масштаба. Увеличение числа потребителей в глобальной экономике последние три десятка лет обеспечивали Китай и другие страны Восточной и Юго-Восточной Азии. Миллиардное население, существовавшее за счет натурального хозяйства, было вовлечено в мировое разделение труда и стало частью мирового рынка. Глобальные корпорации воспользовались этим дважды: путем переноса своих производств в Китай они вытеснили с региональных рынков национальные компании, а за счет экономического развития Китая расширили рынок своих потребителей. К настоящему времени китайский фактор роста мировой экономики практически исчерпал себя.

В период стремительного развития Китая свободная торговля была выгодна всем, в том числе и России, которая обеспечивала сырьем растущую мировую экономику. Но когда мировые рынки перестают расти, Россия остается у разбитого корыта: ни нефтяной "золотой рыбки", ни конкурентоспособной промышленности. Только потребительские запросы населения и геополитические амбиции государства. Западным странам и Китаю тоже непросто, но их промышленность более диверсифицирована, а значит, и более устойчива.

Вернуться из этого кризиса к прежней модели развития, основанной на стимулировании потребительства, будет практически нереально. Можно отложить решение системной проблемы на год, может быть, на несколько лет, но эта отсрочка - за счет увеличения глубины последующего провала. Для новой технологической волны сейчас нет экономической опоры, нет новых потребителей, а те, что есть, не готовы платить больше, они готовы больше потреблять за прежние или за меньшие деньги. Инвестировать в такие изменения выгодно, только если это позволяет значительно расширить свою долю рынка, а расширять ее становится некуда.

\section{МНОГООБРАЗИЕ, ЦЕЛОСТНОСТЬ, МАСШТАБИРУЕМОСТЬ}

Системная проблема состоит в том, что весь мир зависит от крупнейших глобальных корпораций, которые уже поделили рынки и сконцентрировали богатства и управление, а для всех остальных пропадают возможности развития, и они вместе с перспективами теряют мотивацию. Национальные компании не могут отвоевать рынок у глобальных игроков по правилам свободной торговли: слишком различаются весовые категории [4]. А глобальные игроки, добившись доминирующего положения, стремятся сохранить статус-кво, подавляя или поглощая зачатки конкуренции. Им выгоднее консервация, чем развитие партнеров или заказчиков, которое создает предпосылки для появления конкурирующих с ними предложений.

Отвоевать рынок у глобальных корпораций невозможно. Возможно лишь переподчинение другомуглобальному игроку. Этими игроками могут стать китайские компании, которые, завоевав мировой рынок сборочных производств, идут в глубину технологий. Для других стран такая возможность закрыта: их внутренние рынки слишком малы, чтобы вырастить глобальные компании. Всем, кто выбывает из борьбы за глобальное доминирование, остается выживать в сокращающихся по размеру рыночных нишах.

Ситуацию можно сравнивать с Великой депрессией начала прошлого века или даже с кризисом Римской империи. Когда империи достигают предельных размеров, а гражданам не нужно ничего, кроме хлеба и зрелищ, экономика и общество начинают

\section{О०О "КЕКО P"}

Производство и поставка технологических материалов для электронных компонентов на основе керамики: LTCC система SK-47 (керамика, пасты), HTCC система (керамика, пасты).

Керамические и AMB подложки на основе нитрида алюминия и нитрида кремния, а также технологии и оборудование для производства LTCC/HTCC/MLCC/MLCI/PZT/SOFC.

WWW.KEKO-R.RU +7(499) $3980770 \quad$ INFO@KEKO-R.RU

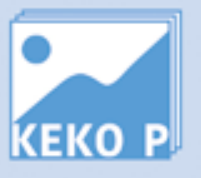


деградировать, а империи - разваливаться. Империями настоящего времени, подчинившими себе весь мир, являются крупнейшие глобальные корпорации.

Худший вариант - если глобализация будет воспринята как причина накапливающихся проблем. Если страны встанут на путь изоляции, разрыва отношений и связей, создания барьеров, то это приведет к многовековому феодальному застою или к войнам. Глобализация является не причиной проблем, а наоборот, великим достижением цивилизации, которое можно и нужно использовать в будущем. Причина проблем в исчерпании возможностей развития с опорой только на безыдейное потребительство и руководство невидимой руки своекорыстных интересов.

И цифровизация может быть как источником новых возможностей и свободы, так и инструментом подчинения. Зависит от того, какие идеи преобладают - эксплуатации человеческих слабостей или, наоборот, их преодоления [5].

Вывести мировую экономику из-под потребительской зависимости от крупнейших корпораций могут идеи, которые ставят совместное долгосрочное развитие выше сиюминутных потребительских интересов. Потребуется восстановление и переосмысление альтруистических идей, признанных общечеловеческими, согласование и внедрение новых норм поведения и взаимоотношений с учетом цифровизации. Эти идеи включают в себя стремление к децентрализации, ассоциированности, взаимной ответственности и взаимной поддержке развития [6].

При этом естественное стремление к комфорту и благополучию не отвергается, но уходит на второй план, как инструмент мотивации, а не цель. Совместное развитие включает в себя увеличение многообразия социальной и технологической экосистем. Увеличение многообразия - это настоящее расширение свободы. Свободы не потребительских слабостей, а выбора возможностей в противостоянии с единообразием, к которому ведет ничем не регулируемое доминирование сильнейшего. Расширение свободы, преодоление экономической и технологической зависимости от крупнейших корпораций потребуют регулирования эгоистического поведения. На это должна быть направлена экономическая и техническая политика государств, политика регулирования торговли.

Ожидаю, что будет всплеск интереса к философии. Вижу это по членам нашей ассоциации. Многие люди и компании оказались в тупике своих прежних идей и начинают искать выход. Семя идеи, брошенное одним, зацепится и разовьется у другого, начнется брожение идей, воздух будет наполнен ими. Это выведет людей из уныния, приведет к активизации общества, в том числе политической.
Пока государства и национальные компании в совокупности имеют ресурсы, хоть и уступающие, но сопоставимые с глобальными корпорациями, их можно мобилизовать на изменения. Чем меньше становится доля национальных компаний, чем выше зависимость от глобальных вендоров, тем дольше будет разложение в потребительском эгоизме, тем глубже будет падение мировой экономики и тем радикальнее и воинственнее будут идеи, которые придут на смену безыдейного потребительства.

Переходя от экономических и социальных вопросов к развитию технологических экосистем, нужно сформулировать общие идеи этого развития.

Как “Свобода, равенство, братство» было лозунгом в борьбе с феодальными ограничениями [7], так сегодня лозунгом борьбы с технологической и экономической зависимостью от глобальных корпораций является "Многообразие, целостность, масштабируемость». Развернуто идеи этого лозунга будут представлены в других статьях. Ниже приводятся только краткие пояснения.

Основой технологического многообразия является концепция вендоронезависимости, которая предполагает следующее:

- совместимость проприетарных решений разных вендоров в проектах одной конечной системы за счет использования открытых стандартизованных интерфейсов и протоколов обмена;

- взаимозаменяемость решений на одной технологической платформе;

- совместное использование, владение и развитие базовых технологий, которые составляют технологические платформы;

- локализация производства конечного оборудования в регионах продаж (базовая идея "Индустрии 4.0»), децентрализация производства базовых компонентов с учетом региональных рисков и диверсификация каналов поставок.

Понятие целостности не предполагает единства, но предполагает охват всех возможностей и совместимость разных подходов к реализации. Целостность рассматривается как синергия различий, как симбиоз, как совмещение отношений кооперации с мотивирующей конкуренцией. Целостность и адаптивность сетевой кооперации в открытых экосистемах рассматриваются как альтернатива единой административной иерархии корпораций. Обеспечение целостности предполагает:

- четкое позиционирование участников, которое способствует развитию кооперации в экосистеме;

- конкурентные отношения участников и дублирование функций, что способствует устойчивости и высокой мотивации; 
- укрепление доверия партнеров по кооперации, заказчиков, инвесторов и даже конкурентов; доверие становится главным активом и дает возможность для экспоненциального роста в сотрудничестве;

- согласование и объединение усилий участников экосистемы в конкуренции с вертикальноинтегрированными корпорациями

Понятие масштабируемости включает в себя возможность тиражирования лучших технических решений разными участниками, снижение барьеров выхода на рынок новых технологий и доступа к инвестициям, необходимым для развития. Масштабируемость в вендоронезависимой концепции предполагается за счет вовлечения участников рынка в свои проекты, а не за счет вытеснения их с рынка. Лучшие решения делают конкурентов партнерами. Это предполагает:

- согласование и типизацию управленческих подходов к созданию новых платформ и новых линеек продукции;

- увеличение количества вендоров - участников экосистемы, расширение линеек продукции и числа проектов внедрения, которые опираются на технологические платформы совместного использования;

- применение государственныхгрантов и государственного финансирования НИОКР на концепты новых платформ совместного использования, разработку базовых технологий совместного владения и первых продуктов на их основе;

- использование венчурных фондов для разработки пилотных продуктов в новых областях применения платформ совместного использования;

- использование отраслевых и межотраслевых фондов развития промышленности для разработки линеек продукции и комплексных решений для крупнейших заказчиков;

- привлечение инвестиций заказчиков на разработку комплексных решений с внедрением платформ;

- предоставление государственных субсидий в качестве финансового плеча для частных инвестиций в проекты внедрения платформ.

Представленные выше условия не являются жесткими, они задают ориентиры для изменений, а не категоричные требования. Так, концепция вендоронезависимости не означает полной независимости от компаний или от их проприетарных технологий, но позволяет управлять рисками, расширяет выбор и повышает степень свободы как для заказчиков, так и для поставщиков.

В концепции вендоронезависимости уже реализуется множество проектов и будет запускаться всё больше. Ниже приведены некоторые из них, инициаторы которых входят в рабочую группу АРПЭ «Вендоронезависимые системы". Если вам интересно участие в этих проектах - они открыты, мы с удовольствием поделимся контактами коллег. Если ваш проект может расширить экосистему вендоронезависимых решений, присоединяйтесь, чтобы вместе уточнять и продвигать концепцию, наполняя ее практическим опытом.

- Доверенная сетевая платформа (https://arpe.bitrix24.ru/ sHvvo).

- Национальная платформа промышленной автоматизации (https://arpe.bitrix24.ru/ XIxPa).

- Платформа умного здания bus77 (https://arpe.bitrix24.ru/ hKwW9)

- Платформа цифровой метрологии TRATES.NET (https://www.soel.ru/magazines/PRINT/ SoEl_2019-9pr/16/index.html).

- Офисный программно-аппаратный стек (https://arpe.bitrix24.ru/ ONjAB).

- Беспроводная технология передачи данных для Интернета вещей GoodWAN (https://goodwan.ru/)

\section{ЛИТЕРАТУРА}

1. Покровский И.А. Понимание цифровой экономики // Новости АРПЭ. 12 апреля 2019 г. - httр://arpe.ru/news/ Ponimanie_tsifrovoy_ekonomiki/?sphrase_id=3755

2. Покровский И. А. Как сохранить доминирование США в полупроводниках? // Группа Facebook «Производство электроники в России". 10 июня 2020 г. https://www.facebook.com/notes/производствоэлектроники-в-россии/как-сохранить-доминированиесша-в-полупроводниках/2639903176251254/

3. Fletcher A. Weaponizing Trade Impacts the Electronics Industry... // IDEA Bulletin. 2019. No. 1. PP. 4-5. https://assodel.it/wp-content/uploads/2019/10/ IDEA-bulletin-oct-2019.pdf

4. Покровский И. А. Цифровая экономика: экосистемы против корпораций // СТИМУЛ. 21 августа 2019 г. - https://stimul.online/viewpoint/tsifrovayaekonomika-ekosistemy-protiv-korporatsiy-i-klanov/ ?fbclid=IWAROxVhGcKGFMb5MuYIfKd-KCoJaAvO_ qrDZolmbmPEmqZRVO-zce7AO7NSI

5. Покровский И.А. Цифровизация наступает. С какой стороны? // Группа Facebook «Производство электроники в России». 20 апреля 2017 г. https://www.facebook.com/notes/производствоэлектроники-в-россии/цифровизация-наступаетс-какой-стороны/1906190216316826/

6. The Declaration of Decentralization // Free TON Community. 2020. - https://freeton.org/dod

7. Скрягин И. Свобода, равенство, братство // Проза.ру. 2014. - https://proza.ru/2014/03/19/1587 
TEХНОСФЕРА

РЕКЛАМНО-ИЗДАТЕЛЬСКИЙ ЦЕНТР

\section{0\% ГАРАНТИЯ ПОЛУЧЕНИЯ ВСЕХ НОМЕРОВ}

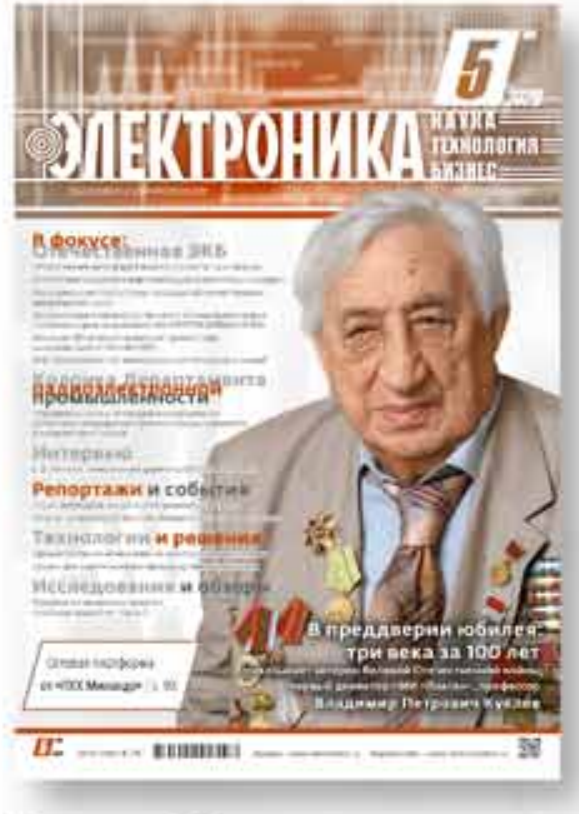

Стоимость 2200 р. за номер

Периодичность: 10 номеров в год www.electronics.ru

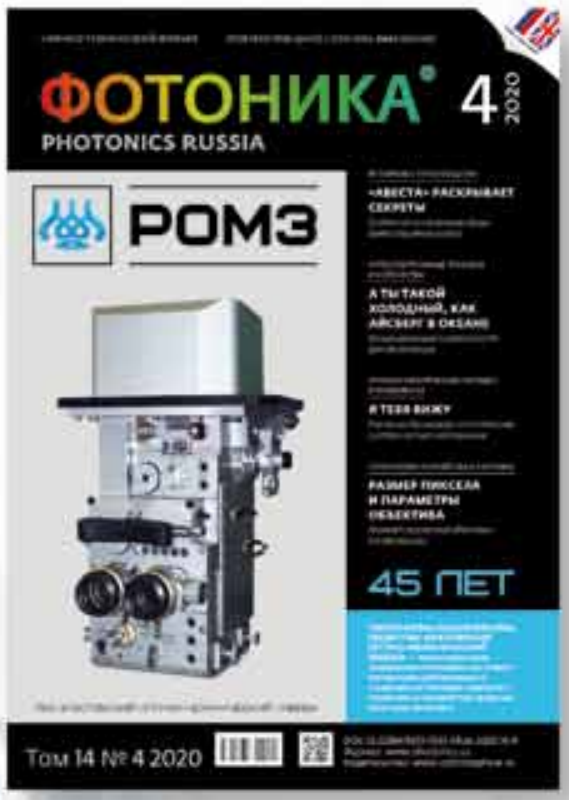

Стоимость 1430 p. за номер

Периодичность; 8 номеров в год www.photonics.su

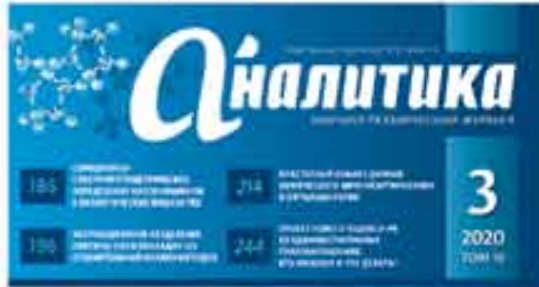

I.Iмсаналитика

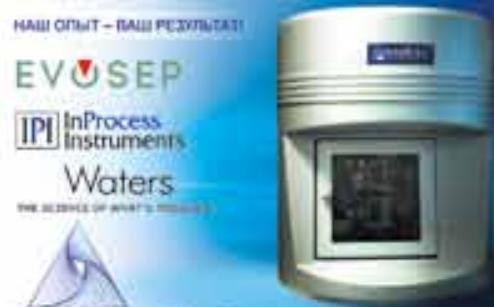

SPECTRA Isotopy

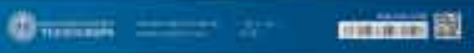

Стоимость 1430 р. за номер

Периодичность: 6 номеров в год www.j-analytics.ru

\section{ПОДПИСКА НА ХУРНАЛЫ}

www.technosphera.ru

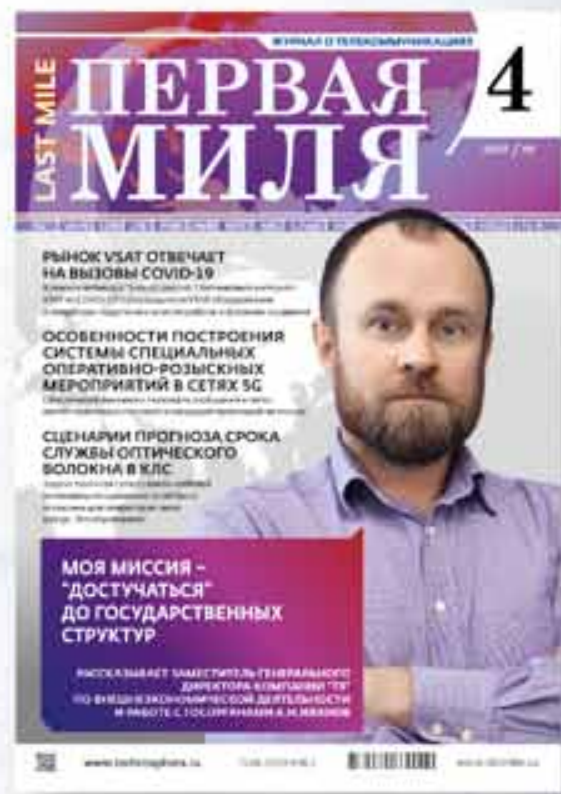

Стоммость 1056 p. за номер

Периодичность: 8 номеров в год www.lastmile.su

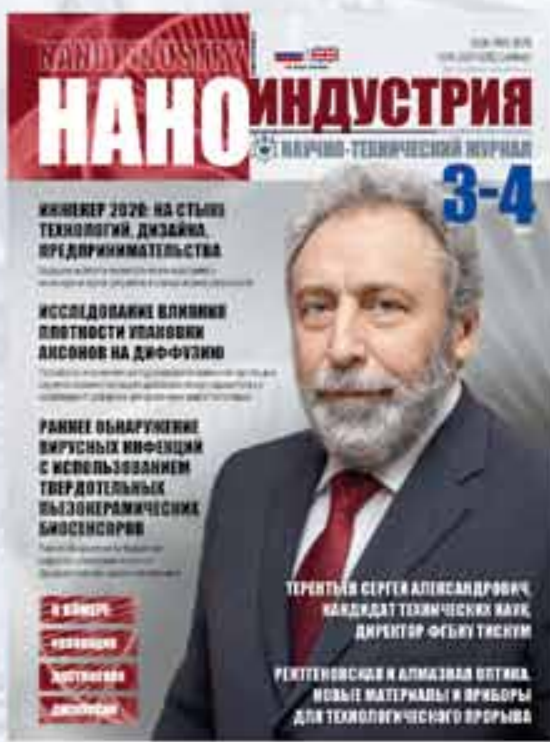

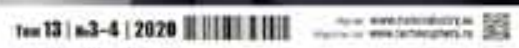

Стоимость 1287 p. за номер

Периодичность; 8 номеров в год www.nanoindustry.su

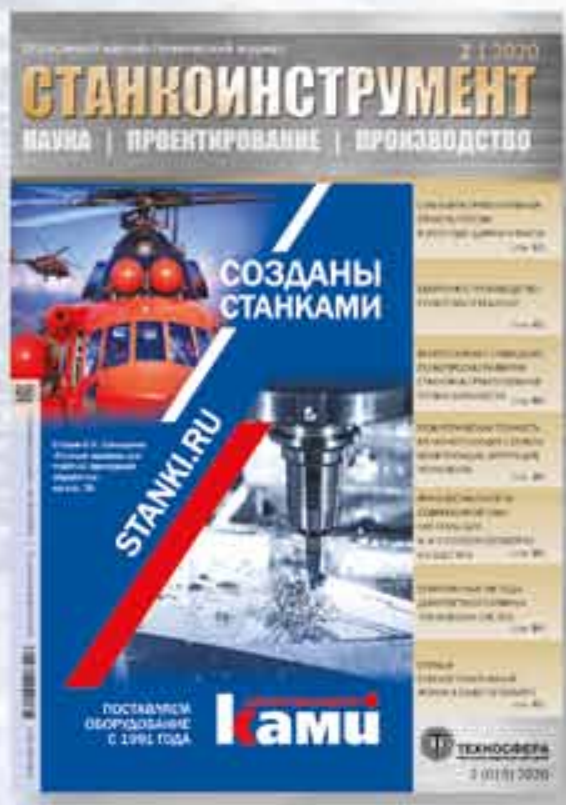

Стоимость 1716 р. за номер

Периодичность: 4 номера в год www.stankoinstrument.su 